\title{
TINJAUAN PELAKSANAAN PEMUSNAHAN REKAM MEDIS RAWAT JALAN TERHADAP EFEKTIVITAS PELAYANAN DI RS X
}

\author{
Jihad Azzaidi ${ }^{* *}$, Muhammad Bayu Herlambang², Irda Sari ${ }^{3}$ \\ Politeknik Piksi Ganesha, Indonesia ${ }^{1,2,3}$ \\ azzaidijihad01@gmail.com ${ }^{1 *}$, muhammadubay40@gmail.com² ${ }^{2}$,irdasari13@gmail.com ${ }^{3}$
}

Received: 05-10-2021

Revised : 23-10-2021

Accepted: 25-10-2021

\begin{abstract}
Abstrak
Latar Belakang: Semakin berkembangnya teknologi di Indonesia, maka semakin tipis pula batas antara informasi yang informatif dengan informasi yang non informative. Begitu juga di dunia kesehatan, semakin berkembang teknologi semakin transparan pula informasi mengenai kesehatan ke khalayak ramai. Bukan hanya mengenai tenaga kesehatannya tapi hingga ilmu kesehatannya pun sedang banyak diperbincangkan sekarang ini. Maka dari itu dibutuhkan penjelasan yang jelas mengenai kesehatan, seperti mengenai pemeliharaan kesehatan, pemeliharaan kesehatan merupakan suatu upaya penanggulangan, dan pencegahan gangguan kesehatan yang memerlukan pemeriksaan, pengobatan ataupun perawatan termasuk kehamilan, dan persalinan.
\end{abstract}

Tujuan: Penelitian ini bertujuan untuk mengetahui bagaimana pelaksanaan pemusnahan rekam medis rawat jalan yang menunjang efektivitas pelayanan di Rumah Sakit $\mathrm{X}$ serta Upaya untuk Pemecahan Permasalahan Dalam Pelaksanaan Pemusnahan Rekam Medis Rawat Jalan di Rumah Sakit X.

Metode: Metode penelitian yang digunakan adalah kualitatif dengan pendekatan deskriptif dan teknik pengumpulan data dengan cara observasi dan wawancara serta melakukan kajian pustaka yang berkaitan dengan pokok permasalahan. Hasil: Hasil dari penelitian, pelayanan yang diberikan dapat dikatakan efektif jika pelaksanaan pemusnahan rekam medis dilakukan secara tepat dan cepat sesuai dengan prosedur dan ketentuan yang berlaku.

Kesimpulan: Berdasarkan penelitian yang dilakukan, ditemukan beberapa permasalahan yaitu: (1) Adanya penumpukkan dokumen yang akan dilakukan penilaian rekam medis in aktif dikarenakan tidak ada ruangan khusus untuk menyimpan dokumen tersebut; (2) Belum adanya jadwal yang spesifik dari rumah sakit mengenai pelaksanaan retensi rekam medis.

Kata kunci: rawat jalan; efektif; pemusnahan rekam medis.

\section{Abstract}

Background: With the development of technology in Indonesia, the boundary between informative and non- 


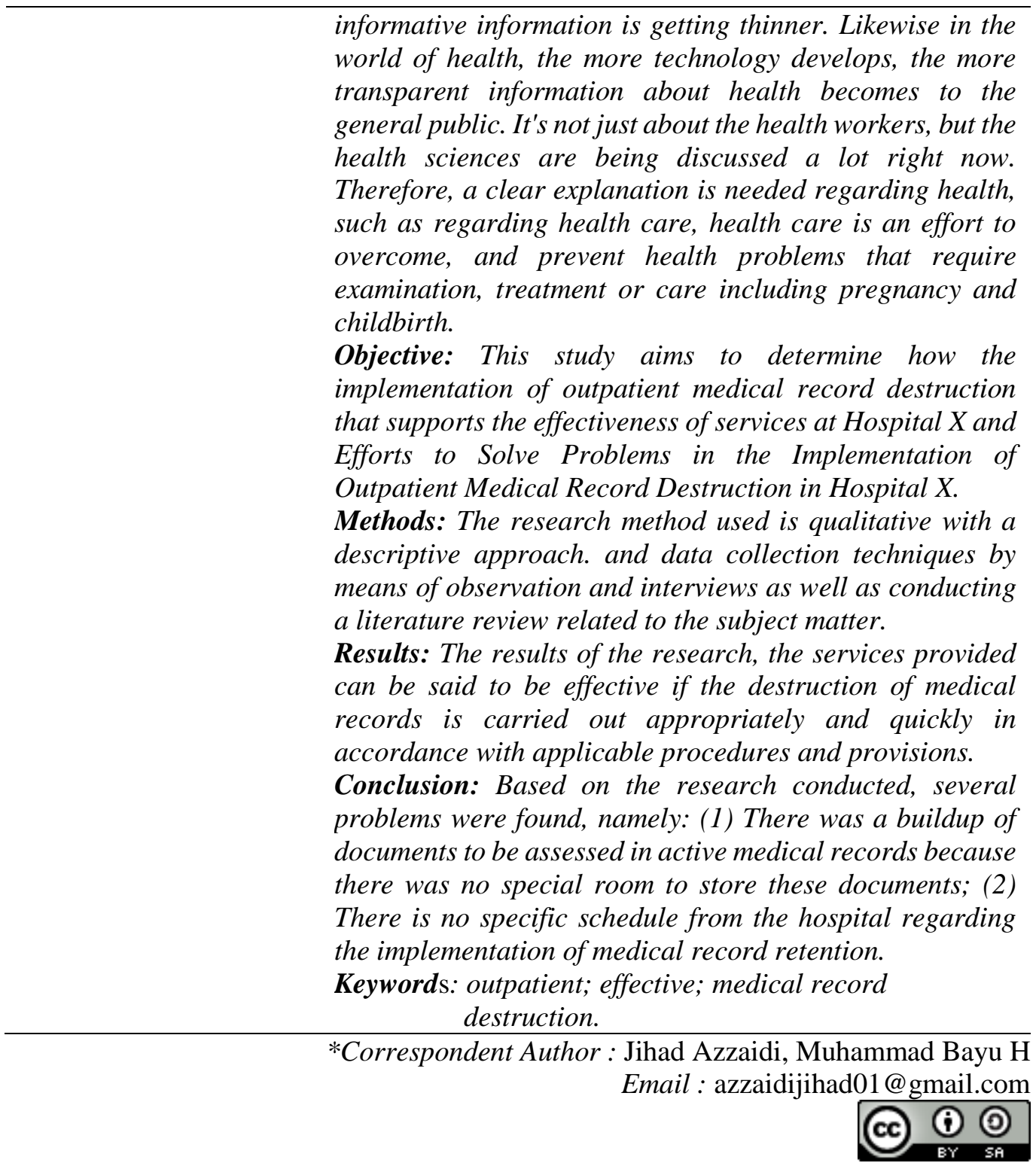

\section{PENDAHULUAN}

Rumah sakit merupakan salah satu tempat pelayanan kesehatan (Maringka, Kawatu, \& Punuh, 2019). Menurut (Anjaryani, 2009), bukan hanya tempat untuk orang sakit tapi juga tempat untuk orang sehat Rumah sakit bukan hanya bersifat rehabilitatif namun juga diperlukan sifat promotif dan preventif di dalamnya dengan maksud sebagai pemberi pengarahan lebih spesifik mengenai kesehatan kepada instansi kesehatan yang lebih rendah ataupun langsung kepada masyarakat.

Unit rekam medis merupakan unit yang mempunyai kegiatan yang beragam, tidak hanya terpaku pada kegiatan pencatatan saja tetapi rekam medis adalah unit yang mengelola data beserta isi dari rekam medis itu sendiri. Pengelolaan yang dimaksud adalah proses pengelolaan data rekam medis pasien dari awal data diberikan sampai data tersebut disimpan dalam rak penyimpanan (Husni, 2019).

Rekam medis harus dikelola dengan baik karena memiliki banyak nilai guna dalam rumah sakit salah satunya adalah menunjang tertib administrasi (Herfiyanti \& Apriyani, 2019). Pengelolaan rekam medis terdiri dari penerimaan pasien; analisis; 
assembling; indeksing; penyimpanan dan pengambilan berkas, retensi dan pemusnahan berkas rekam medis; pelaporan; serta medico legal (Lubis, 2018). Salah satu pengelolaan rekam medis yang sangat perlu dilakukan adalah pemusnahan rekam medis (Hutama \&

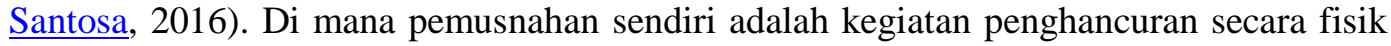
sebuah arsip yang masa fungsinya sudah berakhir dan tidak memiliki nilai guna, rusak atau sudah tidak terbaca lagi (Pujihastuti \& Rohmadi, 2020).

Pemusnahan rekam medis dilakukan dengan salah satu tujuan memberikan ruang lebih untuk penyimpanan rekam medis untuk menyimpan rekam medis yang baru. Hal tersebut dilakukan karena rekam medis tidak disimpan selamanya dan tidak semua data memiliki nilai guna, sehingga diperlukan pemusnahan rekam medis. Dengan dilakukannya pemusnahan rekam medis, ruang penyimpanan lebih kosong dan petugas dapat tetap menjaga kualitas pelayanan, yang salah satunya di unit rawat jalan (Rohman, 2019).

Efektivitas pelayanan kegiatan di Rumah Sakit yang bersifat medis ataupun non medis selalu menjadi sorotan utama baik untuk instansi luar rumah sakit tersebut dan juga untuk para pengunjung rumah sakit (Karina, 2016). Oleh sebab itu, hampir semua hal yang dikerjakan di rumah sakit menjadi tolak ukur seberapa baik efektivitas pelayanan yang diberikan, semakin optimal kinerja yang diberikan di setiap bidangnya maka semakin baik pula efektivitas pelayanan yang dapat dinilai dan diberikan. Pelaksanaan pemusnahan rekam medis pun menjadi salah satu tolak ukur dalam efektivitas pelayanan khususnya di unit rekam medis itu sendiri, entah itu terhadap pasien ataupun terhadap instalasi lain dirumah sakit tersebut (Gustiana, 2016).

Tujuan umum penelitian ini guna untuk mengetahui bagaimana tinjauan pelaksanaan pemusnahan rekam medis rawat jalan terhadap efektivitas pelayanan di RS X. Sedangkan tujuan khususnya untuk mengetahui apa saja permasalahan yang dihadapi dalam pelaksanaan pemusnahan rekam medis rawat jalan terhadap efektivitas pelayanan di RS X. Tinjauan pelaksanaan pemusnahan rekam medis rawat jalan di Rumah Sakit X adalah untuk mengetahui bagaimana efektivitas pelayanan rekam medis di Rumah Sakit X, untuk mengetahui bagaimana tinjauan pelaksanaan pemusnahan rekam medis guna memnunjang efektivitas pelayanan rekam medis di Rumah Sakit X, untuk mengetahui apa saja permasalahan yang dihadapi dalam pelaksanaan pemusnahan rekam medis rawat jalan guna menunjang efektivitas pelayanan rekam medis di Rumah Sakit Umum X.

Berdasarkan hasil praktek kerja lapangan, Rumah Sakit X unit rawat jalan adalah unit yang paling aktif dimana setiap harinya pasien silih berganti berkunjung untuk berobat, mulai dari pasien yang membutuhkan pengobatan ke berbagai poliklinik yang tidak membutuhkan rawat inap. Unit ini merupakan salah satu unit penting dalam Rumah Sakit, di unit rawat jalan inilah pemeliharaan promotif dan preventif digalakan. Unit rawat jalan juga perlu dilakukan pemusnahan rekam medis jika sistem penyimpanan yang digunakan oleh rumah sakit adalah sistem penyimpanan desentralisasi, dengan tujuan yang sama yaitu untuk efesiensi waktu pelayanan kepada pasien. Kegiatan pemusnahan rekam medis ini, dibutuhkan evaluasi dan peninjauan di setiap pelaksanaannya, dilakukannya evaluasi dan peninjauan dengan maksud agar di kegiatan pemusnahan selanjutnya dapat dilakukan lebih optimal dan efektif dari sebelumnya agar dapat menunjang efektivitas pelayanan rekam medis dan juga agar dapat diketahui secara rinci bagaimana kegiatan pemusnahan ini dilakukan.

\section{METODE PENELITIAN}

Penelitian ini menggunakan metode penelitian kualitatif dengan pendekatan deskriptif, yaitu sebuah prosedur penelitian yang menghasilkan data deskriptif berupa kata- 
kata tertulis atau lisan dari orang-orang dan prilaku yang dapat diamati. Menurut YW, Best yang disunting oleh Sanpiah Faisal (Cholid Narbuko dan Abu Achmadi 2016:118) "yang disebut variabel penelitian adalah kondisi-kondisi atau serenteristik-serenteristik yang oleh peneliti dimanipulasikan, dikontrol atau diobservasi dalam suatu penelitian" (Safitriani, Hurmaini, \& Meslita, 2020).

Cholid Narbuko dan Abu Achmadi (2016:61) menjelaskan bahwa variabelvariabel yang akan diteliti harus didefiniskan secara operasional, yaitu definisi yang didasarkan atas sifat-sifat hal yang didefinisikan yang dapat diamati (diobservasi), sehingga apa yang dilakukan oleh peneliti terbuka untuk diuji kembali oleh orang lain.

\section{HASIL DAN PEMBAHASAN}

\section{A. Hasil Penelitian}

Berdasarkan hasil penelitian diketahui penulis melakukan wawancara kepada seluruh petugas mengenai pelaksanaan pemusnahan Rekam medis terhadap efektivitas pelayanan di Rumah sakit untuk mengetahui tentang hubungan pelaksanaan pemusnahan Rekam medis dengan efektivitas pelayanan.

Tabel 1. Hubungan Pelaksanaan Pemusnahan Rekam Medis dengan Efektivitas Pelayanan.

\begin{tabular}{cll}
\hline Variabel & \multicolumn{1}{c}{ Indikator } & \multicolumn{2}{c}{ Keterangan } \\
\hline Pelaksanaan Pemusnahan & SOP & SOP dalam pelaksanaan \\
Rekam Medis Rawat Jalan & SOP Pelaksanaan retensi & pemusnahan dan retensi \\
& dan pemusnahan di unit rekam medis sudah & rem belum \\
& Rekam medis. & terpenuhi namun belan \\
& & memenuhi standar, dimana \\
& & seharusnya ada SOP yang \\
& & lebih terperinci dalam \\
& pelaksanaan retensi rekam \\
& medis.
\end{tabular}

Petugas rekam medis. Jumlah petugas rekam Berjumlah 14 orang medis belum memenuhi petugas rekam medis. standar dimana seharusnya Namun tidak ada petugas ada petugas khusus dalam khusus pelaksana retensi pelaksanaan retensi rekam rekam medis. medis.

\section{Sarana}

Scanner, komputer, sistem input data pertelaan, ruang rekam medis inaktif namun dipakai sebagai ruang penyimpanan rekam medis rawat inap.
Sarana yang ada dalam pelaksanaan pemusnahan rekam medis belum memenuhi standar yang ada dimana seharusnya ruang rekam medis inaktif di gunakan sebagai ruang penyimpanan rekam medis yang sudah inaktif dan akan di lakukan penilaian dan pemusnahan.

\begin{tabular}{lllr} 
Penyusutan Rekam Medis & Pelaksaan & penyusutan \\
Adanya SOP dan SK terkait & rekam medis & belum \\
pelaksanaan penyusutan & & & \\
\hline
\end{tabular}




\begin{tabular}{|c|c|c|}
\hline & $\begin{array}{l}\text { dan retensi rekam medis } \\
\text { namun tidak secara rinci. }\end{array}$ & $\begin{array}{l}\text { memenuhi standar yang } \\
\text { berlaku pelaksanaan. }\end{array}$ \\
\hline \multirow[t]{4}{*}{ Efektivitas Pelayanan } & $\begin{array}{l}\text { Pemusnahan Rekam medis } \\
\text { Adanya SOP dan SK terkait } \\
\text { pelaksaan pemusnahan } \\
\text { rekam medis. }\end{array}$ & $\begin{array}{l}\text { Pemusnahan rekam medis } \\
\text { sudah terpenuhi namun } \\
\text { belum memenuhi standar } \\
\text { yang berlaku. }\end{array}$ \\
\hline & $\begin{array}{l}\text { Faktor waktu } \\
\text { Waktu dalam pemberian } \\
\text { pelayanan rekam medis } \\
\text { terhadap pasien ataupun } \\
\text { tenaga medis lain } \\
\text { (Dokter,Perawat). }\end{array}$ & $\begin{array}{l}\text { Faktor waktu dalam } \\
\text { pemberian pelayanan sudah } \\
\text { cukup baik, namun dalam } \\
\text { pelaksanaan distribusi dan } \\
\text { penyimpanan masih belum } \\
\text { efektif. }\end{array}$ \\
\hline & $\begin{array}{l}\text { Faktor Kecermatan } \\
\text { Ketelitian petugas dalam } \\
\text { pemberian pelayanan. }\end{array}$ & $\begin{array}{l}\text { Faktor kecermatan masih } \\
\text { belum efektif khususnya } \\
\text { dalam pelksanaan distribusi } \\
\text { dan penyimpanan rekam } \\
\text { medis dimana masih di } \\
\text { temukan rekam medis yang } \\
\text { disimpan di nomor rak yang } \\
\text { salah, walaupun tidak } \\
\text { sering di temukan kasus } \\
\text { tersubut, tapi tetap saja hal } \\
\text { tersebut dapat menghambat } \\
\text { pelayanan. }\end{array}$ \\
\hline & $\begin{array}{l}\text { Faktor gaya pemberian } \\
\text { pelayanan } \\
\text { Cara pemberian pelayanan } \\
\text { yang dilakukan oleh } \\
\text { pemberi pelayanan. }\end{array}$ & $\begin{array}{l}\text { Pemberian pelayanan } \\
\text { masih belum efektif dalam } \\
\text { beberapa aspek kusus nya } \\
\text { dalam pelaksanaan } \\
\text { pengiriman dokumen } \\
\text { rekam medis ke poli klinik. }\end{array}$ \\
\hline
\end{tabular}

Berdasarkan tabel 1 di atas dapat diuraikan bahwa efektivitas merupakan suatu tindakan yang membutuhkan ketelitian dan koordinasi yang tinggi dan juga didukung dengan pelaksanaan yang sesuai dengan standar yang berlaku sehingga menghasilkan pelayanan yang tepat, cepat dan tersampaikan maksud atau nilai guna yang diharapkan dapat memenuhi kebutuhan penerima pelayanan dimana yang dimaksud disini adalah pasien. Dimana tercantum dalam tabel diatas bahwa pelaksanaan pemusnahan rekam medis merupakan salah satu faktor penunjang terciptanya pelayanan yang efektif (Siwayana, Purwanti, \& Murcittowati, 2020). Jika pelaksaaan pemusnahan rekam medis dilakukan secara tepat prosedurnya dan tepat pula waktunya, maka pelayanan yang diberikan kepada pasien ataupun petugas medis lain dapat efektif secara waktu ataupun keakuratannya.

\section{B. Pembahasan}

\section{Tinjauan Pelaksanaan Pemusnahan Rekam Medis Rawat Jalan di Rumah Sakit $\mathbf{X}$}

Berdasarkan hasil praktek kerja lapangan yang dilakukan penulis di Rumah Sakit X, pelaksanaan pemusnahan rekam medis rawat jalan di Rumah Sakit X sebagai berikut: 


\section{a. Pelaksanaan Pemilahan dan Pemindahan Rekam Medis Inaktif di Rumah Sakit X}

Dalam pelaksanaan sistem penyimpanan rekam medis di Rumah Sakit X, sistem penyimpanan yang dipakai yaitu sistem desentralisasi dimana rekam medis rawat inap dan rawat jalan disimpan secara terpisah. Untuk sistem penomoran, digunakan cara Unit Numbering System (pemberian nomor secara unit) dalam pelaksanaann ya (Kurniawati \& Asfawi, 2015).

Pemilahan dan pemindahan rekam medis aktif ke inaktif dilakukan untuk mengurangi beban rak dan memberikan ruang untuk rak penyimpanan rekam medis dimana dilakukan langsung oleh petugas rekam medis jika memang dirasa rak penyimpanan sudah penuh dan dibutuhkan ruang lebih untuk menyimpan rekam medis. Seperti yang tertulis dalam SOP pelaksanaan retensi rekam medis Rumah Sakit X, pemilahan rekam medis dilakukan jika rekam medis tersebut sudah masuk dalam batas maksimal rekam medis aktif yaitu 5 tahun dilihat dari tahun terakhir kunjungan pasien tersebut berobat.

\section{b. Pelaksanaan Penilaian Rekam Medis Inaktif di Rumah Sakit X}

Dalam pelaksanaan penilaian rekam medis in aktif di Rumah Sakit X, lembar rekam medis yang memiliki nilai guna dipisahkan dari lembar rekam medis lain dan disimpan di tempat terpisah dari lembar rekam medis yang tidak memiliki nilai guna dimana dalam penumpukannya tetap terurut dari rekam medis terkecil ke rekam medis terbesar. Lembar rekam medis yang dilestarikan di Rumah Sakit X diantaranya :

1) Ringkasan Masuk dan Keluar

2) Resume Medis

3) Lembar Persetujuan (informed consent)

4) Lembar Kematian

5) Laporan Operasi

6) Laporan Persalinan

7) Identifikasi Bayi

8) Data Kelahiran Anak

9) Resume HCU

10) Pemberian informasi medis

\section{c. Pengalih Media Rekam Medis Inaktif di Rumah Sakit X}

Alat yang digunakan : scanner 2 buah, Komputer 4 set, Tenaga kerja 4 orang, Sistem input data pertelaan 2 buah.

Tata pelaksanaan : Proses pengalih media data rekam medis hardcopy ke softcopy adalah kegiatan penduplikasian data rekam medis yang sudah melalui proses penilaian. Sebelum discan, data rekam medis diinput dalam sistem input data pertelaan. Setelah diinput, lembar rekam medis discan.

Pelaksanaan pengalih media di Rumah Sakit X dilakukan dengan maksud untuk melestarikan data rekam medis sebelum dilakukan pemusnahan dan bilamam suatu saat pasien kembali berobat memudahkan untuk melihat kembali riwayat kunjungan dan pengobatan pasien tersebut.

\section{d. Pelaksanaan Pemusnahan Rekam Medis di Rumah Sakit X}

Pemusnahan Rekam Medis di Rumah Sakit X dijelaskan bahwa rekam medis yang sudah memenuhi syarat untuk dimusnahkan dilaporkan kepada Direktur Rumah Sakit dimana pemusnahan dilakukan hanya oleh tim pemusnahan rekam medis yang berkerja sama dengan pihak ketiga. Pemusnahan rekam medis di Rumah Sakit X pertama kali dilakukan pada tahun 2000 dan 
terakhir kali diadakan ditahun 2018 Untuk pelaksanaan pemusnahan sendiri. Rumah Sakit X bekerja sama dengan pihak ketiga, dimana pihak ketiga disini adalah PD X.

Pembentukan tim pemusnahan dilakukan setelah penetapan tanggal pemusnahan. Setelah pembentukan tim pemusnahan, akan dibuat laporan perencanaan pemusnahan yang akan dikirim ke tim pemusnahan termasuk undangan acara pemusnahan. Jika tim pemusnahan sudah mendapat undangan dan laporan perencanaan pemusnahan, rekam medis in aktif yang ada di ruang pemusnahan akan diangkut ke PT X selaku pelaksana pemusnahan dimana rekam medis in aktif akan dimusnahkan disana dengan cara dibuburkan.

\section{Tinjauan Efektivitas Pelayanan Rekam Medis Rumah Sakit X}

Seperti yang telah dijelaskan sebelumnya, bahwa efektivitas pelayanan merupakan suatu batasan atau ukuran yang menilai seberapa jauh target kerja yang telah tercapai. Yang artinya, efektivitas pelayanan merupakan batasan dalam pemberian pelayanan yang memiliki target tersendiri agar dapat dikatakan efektif. Namun, untuk efektivitas pelayanan sendiri memiliki sifat yang subjektif dimana tidak ada patokan khusus dalam penilaiannya .Tergantung siapa yang menilai dan siapa yang dinilai.

Dalam konteks rekam medis, efektivitas pelayanan disini dapat dinilai dalam berbagai aspek bidang rekam medis, bukan hanya pelayanan terhadap pasien namun juga dapat dinilai dari pelayanan terhadap dokter ataupun perawat. Unit rekam medis Rumah Sakit X sendiri jika dilihat secara garis besar, efektivitas pelayanan yang diberikan sudah cukup baik walaupun masih ada beberapa kekurangan.

Berikut ini indikator dari efektivitas pelayanan :

\section{a. Faktor waktu}

Dalam pelaksanaannya, unit rekam medis Rumah Sakit X sudah cukup efektif. Dalam pelaksanaannya, semua aspek bidang di unit rekam medis Rumah Sakit X terintegrasi melalui sistem Hysis dalam pelaksanaan kerjanya, sehingga setiap aspek bagian rekam medis terhubung satu sama lain, seperti pengolahan data rawat inap, rawat jalan, IGD, analisis rekam medis juga pelaporan dapat terpantau dengan baik sehingga kesalahan dapat diminimalisir lebih cepat, maka pelayanan yang diberikanpun dapat dikatakan sudah efektif.

Namun untuk bagian distribusi rekam medis di Rumah Sakit X masih belum efektif. Tercantum dalam laporan standar pelayanan rekam medis pelayanan rawat jalan Rumah Sakit X bahwa waktu penyediaan dokumen rekam medis pelayanan rawat jalan belum memenuhi standar yang ada selama bulan Januari-Juni di tahun 2021 ini . Standar yang ditetapkan untuk pengiriman dokumen rekam medis ke poliklinik seharusnya kurang dari 10 menit dokumen rekam medis sudah ada di poliklinik, namun dalam pelaksanaannya rata-rata setiap bulannya rekam medis sampai di poliklinik lebih dari 10 menit, maka untuk bagian distribusi rekam medis dapat dikatakan belum efektif.

\section{b. Faktor Kecermatan}

Kecermatan atau ketelitian sangat diperlukan dalam pelaksanaan pelayanan rekam medis, begitu juga di unit rekam medis Rumah Sakit X, ketelitian sangat diutamakan dalam pelaksanaan kegiatan rekam medis karena dapat berpengaruh dalam pemberian pelayanan terhadap pasien dan juga berpengaruh pada isi data yang akan dilaporkan.

Dalam pelaksanaannya, unit rekam medis di Rumah Sakit X jika dilihat masih belum efektif terutama dalam pelaksanaan penyimpanan rekam medis rawat jalan. Masih ada ditemukan rekam medis yang disimpan di nomor rak yang 
salah, walaupun tidak sering ditemukan kasus tersebut, tapi tetap saja hal tersebut dapat menghambat pelayanan.

\section{c. Faktor Gaya Pemberian Pelayanan}

Gaya pemberian pelayanan artinya cara pemberian pelayanan yang dilakukan oleh pemberi pelayanan. Pemberian pelayanan di rekam medis membutuhkan penunjang agar pelayanan yang diberikan lebih optimal, dan biasanya penunjang tersebut berupa sarana, prasarana dan juga sumber daya manusia sebagai pemberi pelayanan yang dimana pemberi pelayanan disini merupakan petugas rekam medis.

Rumah Sakit X sendiri, untuk cara pemberian pelayanan masih belum cukup efektif dalam beberapa aspek, yang salah satunya adalah seperti yang dijelaskan sebelumnya bahwa dalam pelaksanaan pengiriman dokumen rekam medis ke poliklinik belum memenuhi standard yang ada, sehingga hal tersebut dapat menghambat dalam pemberian pelayanan terhadap pasien. Walaupun dalam aspek lain seperti cara pemberian informasi kepada pasien dimana petugas menjelaskan dan menjawab keluhan pasien menggunakan bahasa yang santun dan dapat dimengerti oleh pasien tersebut tanpa menyinggung perasaan pasien.

\section{Tinjauan Pelaksanaan Pemusnahan Rekam Medis Rawat Jalan Terhadap Efektivitas Pelayanan Di Rumah Sakit X}

Suatu kegiatan dapat dikatakan sudah efektif apabila telah memenuhi target ataupun tingkat kepuasan yang di inginkan, dan untuk mencapai hal tersebut dibutuhkan koordinasi yang baik dan tepat sesuai dengan standar operasional yang ada disetiap aspek kerja yang ada dalam unit tersebut. Begitu juga dengan unit rekam medis, dimana untuk dapat menciptakan sistem kerja rekam medis yang sesuai dengan kegunaannya dibutuhkan kecermatan dan integrasi yang baik yang sesuai dengan ketentuan yang telah ditetapkan setiap bidangnya, termasuk dalam pelaksanaan pemusnahan rekam medis yang sesuai dengan prosedur yang berlaku.

Ditetapkannya ketentuan standard operasional prosedur pelaksanaan pemusnahan rekam medis dimaksudkan agar pelaksanaan pemusnahan rekam medis terstruktur, teratur dan teradministrasi dengan baik. Dapat dilihat dalam penjelasan mengenai pelaksanaan pemusnahan rekam medis di Rumah Sakit X bahwa dalam pelaksanaannya SPO yang ada mengenai pelaksanaan retensi dan pemusnahan rekam medis ditaati dengan baik dengan maksud dalam pelaksanaannya, petugas melakukan retensi dan pemusnahan sesuai dengan SPO yang berlaku. Sehingga diharapkan dapat terciptanya efektivitas pelayanan di Rumah Sakit X berjalan dengan baik dan sesuai dengan target yang diharapkan.

\section{KESIMPULAN}

Berdasarkan hasil praktek kerja lapangan yang dilakukan penulis di Rumah Sakit $\mathrm{X}$, penulis mengambil kesimpulan di antaranya pelaksanaan Pemusnahan Rekam Medis Rawat Jalan di Rumah Sakit X pada umumnya pelaksanaan pemusnahan rekam medis rawat jalan di Rumah Sakit X sudah terlaksana dengan baik, dengan efektif dan semaksimal mungkin. Untuk hambatan sendiri, hambatan yang dialami dalam pelaksanaan pemusnahan rekam medis rawat jalan hanya berkenaan dengan tempat penyimpanan rekam medis in aktif, di mana untuk menyimpan dokumen rekam medis inaktif sendiri masih berantakan karena tidak adanya tempat khusus untuk menyimpan dokumen-dokumen rekam medis yang sedang dan akan dilakukan retensi. Rekam medis hanya disimpan di area kosong di 
ruang penyimpanan ataupun ruangan rekam medis seperti di area tangga atau lorong di ruang penyimpanan rekam medis.

Efektivitas Pelayanan Di Rumah Sakit X, dapat dikatakan bahwa efektivitas pelayanan merupakan suatu batasan atau ukuran yang menilai seberapa jauh target kerja yang telah tercapai Berikut ini adalah indikator efektivitas pelayanan faktor waktu, faktor kecermatan, faktor gaya pemberian pelayanan. Dalam pelaksanaannya, efektivitas pelayanan di Rumah Sakit X sudah cukup efektif meskipun dalam beberapa aspek kerja masih belum bisa dikatakan efektif. Namun secara keseluruhan efektivitas pelayanan di Rumah Sakit X sudah dapat dikatakan efektif.

Tinjauan Pelaksanaan Pemusnahan Rekam Medis Rawat Jalan Terhadap Efektivitas Pelayanan Di Rumah Sakit X, dapat diuraikan bahwa efektivitas merupakan suatu tindakan yang membutuhkan ketelitian dan koordinasi yang tinggi dan juga didukung dengan pelaksanaan yang sesuai dengan standar yang berlaku sehingga menghasilkan pelayanan yang tepat, cepat dan tersampaikan maksud atau nilai guna yang diharapkan dapat memenuhi kebutuhan penerima pelayanan dimana yang dimaksud disini adalah pasien. Dalam tabel hasil pengolahan penulis dijelaskan bahwa pelaksanaan pemusnahan rekam medis merupakan salah satu faktor penunjang terciptanya pelayanan yang efektif. Jika pelaksaaan pemusnahan rekam medis dilakukan secara tepat prosedurnya dan tepat pula waktunya, maka pelayanan yang diberikan kepada pasien ataupun petugas medis lain dapat efektif secara waktu ataupun keakuratannya.

Permasalahan Dalam Pelaksanaan Pemusnahan Rekam Medis Rawat Jalan di Rumah Sakit X, berdasarkan hasil praktek kerja lapangan yang dilakukan penulis di unit rekam medis Rumah Sakit X khususnya di bagian retensi rekam medis, pelaksanaan dalam retensi pemusnahan rekam medis mengalami beberapa masalah diantaranya adanya penumpukkan dokumen yang akan dilakukan penilaian rekam medis inaktif dikarenakan tidak adanya ruangan khusus untuk menyimpan dokumen tersebut, belum ada jadwal yang spesifik dari rumah sakit mengenai pelaksanaan retensi rekam medis.

Upaya Pemecahan Permasalahan Dalam Pelaksanaan Pemusnahan Rekam Medis Rawat Jalan di Rumah Sakit X, dari permasalahan yang telah dijelaskan sebelumnya, adapun upaya yang sedang dilakukan oleh pihak unit rekam medis Rumah Sakit X adalah sejauh ini, Kepala Urusan Rekam Medis Rumah Sakit X sudah melakukan pengajuan penambahan rak untuk penyimpanan rekam medis, namun memang belum ada tindakan yang ditunjukkan dari pihak terkait untuk merespon pengajuan dari pihak unit rekam medis Maka untuk saat ini dokumen rekam medis in aktif disimpan di area kosong di ruangan rekam medis ataupun di ruang penyimpanan rekam medis, dilakukan retensi setiap 1 tahun sekali agar rak penyimpanan rekam medis setiap tahunnya berkurang dan memanfaatkan adanya mahasiswa PKL yang ada di unit rekam medis Rumah Sakit X Dimana setelah mahasiswa PKL selesai, rekam medis yang belum selesai proses retensinya akan dilanjutkan oleh para petugas rekam medis dengan menyempatkan waktu kerja dan melaksanakan lembur kerja.

\section{BIBLIOGRAFI}

Anjaryani, Wike Diah. (2009). Kepuasan pasien rawat inap terhadap pelayanan perawat di RSUD Tugurejo Semarang. Universitas Diponegoro.

Gustiana, Riri. (2016). Efektivitas Pelayanan Pembuatan Kartu Tanda Penduduk Elektronik (E-KTP) Pada Kantor Kecamatan Baamang Kabupaten Kotawaringin Timur. Journal Ilmu Sosial, Politik Dan Pemerintahan, 5(1), 1-14.

Herfiyanti, Leni, \& Apriyani, Ria Khoirunnisa. (2019). Pengaruh Beban Kerja Terhadap Kelancaran Verifikasi Klaim Bpjs Di Klinik Utama Medika Antapani Bandung. INFOKES (Informasi Kesehatan), 3(1), 58-67.

Husni, M. Afif Rijal. (2019). Development of the Medical Record File Folder Design in 
Medical Record Unit RSUD dr. H. Slamet Martodirdjo, Pamekasan city. JURNAL MEDICAL P-ISSN: 2685-7960 e-ISSN: 2685-7979, 1(1), 44-48.

Hutama, Hafid, \& Santosa, Erwin. (2016). Evaluasi Mutu Rekam Medis di Rumah Sakit PKU 1 Muhammadiyah Yogyakarta: Studi Kasus pada Pasien Sectio caesaria. Jurnal Medicoeticolegal Dan Manajemen Rumah Sakit, 5 (1), 25-34.

Karina, Riska. (2016). Kualitas Pelayanan Kesehatan Pada Pasien Rawat Inap Kelas Iii di Rumah Sakit Umum Daerah (RSUD) Kota Cilegon. Universitas Sultan Ageng Tirtayasa.

Kurniawati, Arum, \& Asfawi, Supriyono. (2015). Analisis Deskriptif Faktor Penyebab Kejadian Missfile di Bagian Filling Rawat Jalan RSUD Dr. M. Ashari Pemalang Tahun 2015. Jurnal. Http://Eprints. Dinus. Ac. Id/17447//. Pdf (1 Maret 2020).

Lubis, Hendarman. (2018). Perancangan Sistem Informasi Rekam Medis Persalinan Menggunakan Teknologi CHIPS RFID E-KTP Sebagai Kartu Pasien Dengan Metode Rapid Application Davelopment. Jurnal SIGMA, 8(1), 95-104.

Maringka, Ferlina, Kawatu, Paul A. T., \& Punuh, Maureen I. (2019). Analisis Pelaksanaan Program Kesehatan dan Keselamatan Kerja Rumah Sakit (K3RS) di Rumah Sakit Tingkat II Robert Wolter Mongisidi Kota Manado. KESMAS, 8(5), 1-10.

Pujihastuti, Antik, \& Rohmadi, Rohmadi. (2020). Tata Kelola Ruang Filing Di Uptd Puskesmas Masaran Ii Kabupaten Sragen. Prosiding" Penguatan Pendidikan Tenaga Kesehatan Di Era Industri 4.0".

Rohman, Hendra. (2019). Sistem Retensi Berkas Rekam Medis Terintegrasi: Perancangan Sistem Informasi Berbasis Web di Klinik Pratama. Jurnal Manajemen Informasi Dan Administrasi Kesehatan (JMIAK), 2(2).

Safitriani, T. M., Hurmaini, Hurmaini, \& Meslita, Rima. (2020). Pengaruh Penggunaan Multimedia Macromediaflash Terhadap Kemampuan Penalaran Matematika Peserta Didik Madrasah Tsanawayah Laboratorium Kota Jambi. UIN Sultan Thaha Saifuddin Jambi.

Siwayana, Putu Adiz, Purwanti, Ika Setya, \& Murcittowati, Putu Ayu Sri. (2020). Tinjauan Literatur: Faktor-Faktor Penyebab Ketidaklengkapan Pengisian Rekam Medis Rawat Inap Rumah Sakit Literature Review: Factors Causing incompleteness Filling Medical Records In Hospital. Jurnal Rekam Medis Dan Informasi Kesehatan, 3(2).

(C) 2021 by the authors. Submitted for possible open access publication under the terms and conditions of the Creative Commons Attribution (CC BY SA) license (https://creativecommons.org/licenses/by-sa/4.0/). 